\title{
Proposed Canterbury Natural Resources Plan for river and groundwater allocation policies and the implications for irrigation dependent farming in Canterbury
}

\author{
M.G. MILLER and A. VELTMAN \\ Planning Natural Resource Section, Environment Canterbury
}

\begin{abstract}
Over $60 \%$ of the water that is used for irrigation throughout New Zealand is allocated within the Canterbury Region. In 1985 around 150000 hectares of land was irrigated, in 1999 this had more than doubled and the Canterbury Strategic Water Study ${ }^{1}$ has estimated there is potential in Canterbury to irrigate up to 1000000 hectares. As the demand for water increases the conflicts are likely to increase. These conflicts may be between users, between those who have access to water and those who don't but would like some, or between existing and potential users and environmental interests.

Environment Canterbury has recently notified a major variation to its Natural Resources Regional Plan that includes policies for the management of water, intended to help address the conflicts between the use, development and protection of the regions water resources. This paper and presentation outlines and backgrounds the allocation strategies included in Chapter 5 - Water Quantity and discusses some of the implications for irrigation dependent farming.
\end{abstract}

\section{Introduction}

The RMA does not require the development of a Regional Plan to address the management of water resources but it does recognise in $\mathrm{s} 65$ that there are circumstances where it might be desirable to prepare one. These include when the following circumstances or considerations are likely to arise:

(a) Any significant conflict between the use, development, or protection of natural and physical resources or the avoidance or mitigation of such conflict.

(b) Any foreseeable demand for or on the natural and physical resources.

In Canterbury there is foreseeable demand for more water to be taken and for this to compound some of the environmental effects as well as conflict with existing users access to the resource. This raises the issue of how much more should be allocated from each water resource?

Environment Canterbury has established policy and methods in the Natural Resources Regional Plan to address this issue.

The water quantity chapter firstly addresses the issue of the effects of activities (taking, diverting, damming and using of water) on the environment and secondly addresses the issue of allocation of water above any set flow or level regime to out-of-stream/consumptive uses, and its efficient use. It is this area of allocation and efficient use of water that is discussed in this paper. This discussion outlines the strategy that is incorporated in the NRRP to establish interim and permanent allocation regimes for the region's water bodies.

\section{Allocation regimes - reliability of supply}

Policy WQN14 in Chapter 5 of the Natural Resources Regional Plan sets out Environment Canterbury's approach to water allocation. The intention of the NRRP is to set allocation regimes for all surface water and groundwater water bodies from which water is being taken or likely to be taken throughout Canterbury. It is considered that it is necessary to do this to achieve equitable and reliable distribution of the resource. The concern is that if there is no limit to the allocation of water from a particular resource then the increasing cumulative take will come under restriction more frequently and for longer periods. The risk is that this will compromise the activities that are dependent on a reliable share of the resource.

For the purposes of this discussion, it is assumed for surface water bodies, that a flow regime will be established that addresses the instream flow requirements. This may simply set a minimum flow but it may also include flow sharing and other attributes. Having set flow regimes, allocation limits will follow ${ }^{2}$. For groundwater bodies the allocation limit may also address management of the environmental effects.

To develop an approach for determining allocation limits ECan commissioned Lincoln Environmental in 2001 (report U01/1) to assess what reliability of supply is necessary for irrigation in Canterbury ${ }^{3}$. This work

\footnotetext{
1 The Canterbury Strategic Water Study was prepared for Environment Canterbury, MAF, and MFE by Lincoln Environmental to look at the potential long-term requirement for water, and the capacity of the region to meet those requirements.

2 It may be that the flow and allocation are worked through concurrently, with the possible outcome of setting an allocation regime that by it's approach addresses instream flow requirements as well.

${ }^{3}$ Irrigation was chosen as this is the principal use of the water that is abstracted from Canterbury's water bodies. Of course hydro electricity generation also uses large volumes of water.
} 
Table 1 Irrigation reliability of supply options.

Reliability Option 1 Allocate so that every year restrictions are no more than a level that can be addressed by on farm management with no significant decrease in annual profit.

Reliability Option 2 Allocate so that in 4 out of 5 years restrictions can be addressed by on-farm management with no significant decrease in annual profit, and with only 1 year in 20 subject to a severe event that causes a significant decrease in annual profit.

Reliability Option 3 Allocate so that in 3 out of 5 years restrictions can be addressed by on-farm management with no significant decrease in annual profit, and 1 year in 10 subject to a severe event, causing a significant decrease in annual profit.

Table 2 Allocable surface water for Rangitata, Waimakariri and Ashburton rivers based on rigorous method.

\begin{tabular}{ccc}
\hline $\begin{array}{c}\text { Pastoral } \\
\left(\mathrm{m}^{3} / \mathrm{s}\right)\end{array}$ & Arable cropping & Horticulture \\
\hline
\end{tabular}

RELIABILITY OPTION 1

Rangitata River

Waimakariri River

Ashburton River

\section{RELIABILITY OPTION 2}

Rangitata River

Waimakariri River

Ashburton River

\section{RELIABILITY OPTION 3}

Rangitata River

Waimakariri River

Ashburton River

Allocable surface water flows that meet the "high" threshold in all years

$\begin{array}{ccc}29 & 31 & 27 \\ 0 & 0 & 0 \\ 3.9 & 4.3 & 3.3\end{array}$

Allocable surface water flows that meet the "high" threshold in 4 out of 5 years, and the "low" threshold in 19 out of 20 years

$\begin{array}{ccc}36 & 41 & 31 \\ 0 & 0 & 0 \\ 7.1 & 9.3 & 6.2\end{array}$

Allocable surface water flows that meet the "high" threshold in 3 out of 5 years, and the "low" threshold in 9 out of 10 years

$\begin{array}{ccc}39 & 46 & 36 \\ 0 & 11 & 0 \\ 9.2 & 11.2 & 6.8\end{array}$

Note: Allocable flows exclude stockwater takes of 1, 3.8 and 4.6 from the Rangitata, Waimakariri and Ashburton rivers, respectively

examined the factors that affect the ability of irrigators to accept water restrictions, identified water availability thresholds, defined three reliability of supply options for allocating water and tested them for surface and groundwater resources.

The report described the three reliability of supply options ${ }^{4}$ qualitatively as described in Table 1.

By testing these in three rivers and for a groundwater resource the report identified how much water could be allocated under the three different reliability options. The findings were reported in Tables 5 and 8 of that report. These have been reviewed since then in a second report by Lincoln Environmental (U03/9) and are shown in Table 2.

Of note is that with the current effective allocation from the Rangitata River, the reliability level for pastoral use lies somewhere between reliability option 1 and reliability option 2 . For the Waimakariri River, without even considering the effective allocation, the reliability level is worse than reliability option 3 for pastoral use but it does allow for an 11 cumec allocation for arable cropping at reliability option 3. (The Waimakariri River Regional plan sets an A Permit allocation limit of 22 cumecs.) For the Ashburton River/Hakatere with the current effective allocation, the reliability level is poorer than reliability option 3 .

ECan has chosen to target reliability option 3 for surface water bodies and reliability option 2 for groundwater bodies. This is set out in Policy WQN14 of Chapter 5 of the NRRP. The reasons for taking this approach are discussed later.

The Lincoln Environmental report U01/1 identified the need for further work. It included the need to test the approach to groundwater, to test the approach for surface water further to see if it could be applied on a river type basis, and to carry out an economic analysis.

\footnotetext{
${ }^{4}$ This concept of reliability of supply is not that easy to understand. The Canterbury Strategic Water Study described this same approach as follows:

Allocate so that there is "noticeable" restrictions for no more than 2 years in 5, or "severe" restrictions for no more than 1 year in 10.

Where:

- Noticeable restrictions are when restrictions, of any degree, occur for more than $20 \%$ of the irrigation season.

- Severe restrictions are when a greater than $50 \%$ restriction level is imposed for more than $20 \%$ of the irrigation season.
} 
The first two matters are discussed further below. With regard to the economic analysis MAF took the initiative to undertake a study in conjunction with ECan, to test this trade-off between individual reliability (and viability) and regional benefit. This study is close to completion. From the drafts we have seen, of particular interest to ECan is that the report indicates a significant regional economic benefit from allocating more water from a water resource over a wider area (but with a greater number of days of restriction for each take), compared with providing higher reliability of supply to a smaller number of abstractors.

\section{Surface water - allocation regimes}

The Lincoln Environment (U01/1) report didn't recommend any specific approach considering it to be a political call as to which reliability standard to adopt and also which land use the reliability should be set for. As mentioned earlier, ECan has set reliability option 3 as the level to guide the setting of allocation limits for surface water bodies. This is the aim when setting interim allocation limits for surface water using Schedule WQN2.

As allocation limits are discussed with the community with the intention of bringing them into Schedule WQN1 (surface water), reliability option 3 is intended to guide the discussion but there is opportunity for that particular community to set a higher or lower level of reliability if that is what they wish. This is effectively reflected in the Waimakariri River Regional Plan ${ }^{5}$ where an allocation limit of 22 cumecs is set but as is evident from Table 1, no water would be available for allocation for pastoral use, if the reliability option 3 were to be achieved. A consequence of this is that we are seeing applications by irrigators within the Waimakariri Irrigation Scheme applying for ground water to supplement their surface water take.

For the surface water bodies in Table 1 the results were obtained by analysing the flow records to determine the flows that yielded the necessary reliability of supply. For the Rangitata and Waimakariri Rivers this was reasonably simple because the flow data was available from monitoring sites that lie upstream of any takes. For the Ashburton River/Hakatere this was more complicated because the minimum flow site is downstream of takes. This means the flow record is distorted by the abstractions. For this reason it was necessary to simulate an unmodified flow record for the river. This work was carried out in-house by Graeme Horrell ${ }^{6}$ and has been updated since the initial Lincoln Environmental work. This update, smoothing of the data and application of an alternative minimum flow for the Ashburton river at State Highway 1 site has changed the allocation amount derived in the two Lincoln Environmental reports (from 13.5 cumecs to 11.8 cumecs $\left.{ }^{7}\right)$.

In summary the NRRP approach is to set specific catchment flow and allocation regimes and include these in Schedule WQN1 OF Chapter 5. In the interim an approach is included for other surface water bodies in Schedule WQN2.

\section{Ashburton River/Hakatere - an example of a Schedule WQN1 catchment-specific flow and allocation regime}

The Ashburton River/Hakatere is a catchment that has a flow and allocation regime set in Schedule WQN1. An A allocation limit of 11.8 cumecs is included in the Schedule. This reflects the amount of water that is estimated as being available for allocation from within the catchment to provide the option three reliability for irrigation dependent pastoral farming. There is potential to allocate more for irrigation dependent arable cropping farming. Obviously there is a mixture of land use across the Ashburton area serviced by Ashburton river water. Pastoral use is dominant, with an estimated $14 \%$ of the area used for arable cropping ${ }^{8}$. By setting the reliability based on pastoral demands, irrigation dependent arable cropping has better reliability.

The effective allocation from the Ashburton catchment is calculated to be 14.531 cumecs and on this basis the A allocation block is over allocated. This will impact on the actual reliability of supply. It will mean that abstractors will experience more restrictions than indicated for reliability option three.

The NRRP addresses this situation. It allows that an allocation block limit can be exceeded. This can occur because the water permits have been issued prior to the flow and allocation regime being settled, as is the case for the Ashburton River/Hakatere. ECan doesn't propose that consents issued prior to January 2002 should be reduced in this situation simply to fit the

\footnotetext{
${ }^{5}$ Note the Waimakariri River Regional Plan is a separate plan, and the reliability of supply approach in the NRRP had not been developed at the time the plan was being prepared.

${ }^{6}$ This is reported in reports $U 01 / 26$ and $\cup 03 / 28$.

7 The Ashburton figure is derived from the reference flow of $17.8 \mathrm{~m}^{3} / \mathrm{s}$ less the proposed minimum flow of $6 \mathrm{~m}^{3} / \mathrm{s}$. There are complications due to the fact that stockwater has different restrictions applying that give it greater reliability and the irrigation share lesser reliability which explains why this figure does not correspond with the figure of $9.2 \mathrm{~m}^{3} / \mathrm{s}$ shown on Table 1 .

${ }^{8}$ Derived from land use data for the Ashburton area recorded in Report U04/15/2 - The economic Impact of proposed management options of the Ashburton - Hakatere River.
} 
allocation block limit. It does propose to review permits to bring them into line with the new flow regime when this becomes operative, and when doing this it also intends to review the water use requirements of the activity. If more water is taken than can be justified this surplus amount should be relinquished. Where it is relinquished it won't be reallocated unless collectively this approach has dropped the effective allocation to less than the allocation block limit. Where a water permit that has been issued prior to January 2002 expires, the water permit may be replaced and remain in the same allocation block. This recognises that the take is already being counted in this block and that the property has been developed and is dependent on this water permit. Reasonable and actual use will be tested and surplus water relinquished at the time of expiry and replacement, if it hasn't been reviewed prior to this.

Where a water permit has been allocated water for the first time from January 12002 or later, then once an allocation limit is set in Schedule WQN1 and the effective allocation is in excess of the limit, the proposed NRRP intends that the water permit will be reviewed and assigned as a take from the (less reliable) B Allocation block.

In the Ashburton River/Hakatere case the B Permit minimum flow is set at 14 cumecs at State Highway 1 . This intention to reassign takes to the B Allocation Block is important to note. Initially only a few surface water bodies will have allocation limits set in Schedule WQN1. More will be introduced as variations or changes to the NRRP. In the interim there is a possibility that water could be allocated that will exceed the final allocation limit. This could arise because the minimum flow is raised increasing the frequency of restrictions. This is what has happened with the Ashburton River/Hakatere.

While discussing the Ashburton River/Hakatere it is worth commenting on some of the other issues arising there. An alternative flow regime has been proposed that, at the State Highway 1 bridge, is higher than the status quo in some months, though it is the same as, or lower than the status quo flows in winter and spring. This may improve access to the resource for winter/ spring use for hydro electric generation and for out-ofseason storage, but it increases the pressure in the summer and autumn months. The flow regime is justified in terms of the flows that are required to maintain the life-supporting capacity of the instream values (including trout and salmon).

Having set the flow regime ECan are keen to avoid flows from receding below this. With this in mind, stock water takes become an issue.

In the past the stockwater water permits have had no conditions that required any reduction of the amount of water taken during periods of minimum flow. There is provision in the RMA that gives a degree of priority to water for an individual's reasonable domestic needs and for the reasonable needs of an individual's animals for drinking water. There is also a proviso that this take does not or is not likely to have an adverse effect on the environment. A large amount ${ }^{9}$ of water is taken for community stockwater schemes from the Ashburton River/Hakatere and conveyed via open races. Of the amount taken an estimated $5 \%$ is required for stock drinking, the majority is lost to ground along the way.

ECan has judged that these takes will have an adverse environmental effect at times of minimum flow if they continue to take the full amount. The NRRP looks to restrict these to $20 \%$ of their allocated amount when the minimum flow is reached. This restriction is to be phased in once the plan is operative to allow the community time to find ways to manage around this restriction. Solutions include moving to alternative sources, strategically piping stockwater, or river enhancement that avoids the minimum flow from being triggered.

Needless to say there is criticism of and opposition to this proposal. Arguments in opposition include the cost of piping or changing the $3600 \mathrm{~km}$ network of races, the rate of change ${ }^{10}$, the fact that stockwater races also supply household water, that they provide fire fighting water, that they support ecological values, and that the loss to ground recharges ground water.

In developing the flow and allocation strategy for the Ashburton River/Hakatere, ECan looked at the effect of the changes on existing irrigators and other water users ${ }^{11}$. These indicated that reducing the stockwater takes to $20 \%$ of the current allocation would generally offset the effect of raised minimum flows. So, for the cost of changing and upgrading stockwater, the existing reliability and economic output could be maintained. The cost of upgrading, and the fact that those who maintain their irrigation reliability may not necessarily be the one's who bear the cost of any stockwater upgrades, didn't provide a lot of incentive to achieve this change.

An alternative strategy, that allows the stockwater that is saved, to be transferred to irrigation use was tested. This strategy potentially frees up water to irrigate an additional 8220 hectares. The increased output from this

\footnotetext{
${ }_{9}$ Ashburton District Council exercise water permits to take 4.639 cumecs of water from the Ashburton River/Hakatere.

${ }^{10} \mathrm{ADC}$ has an aim of closing $100 \mathrm{~km}$ of stockwater races per year. This is included as an objective of the Ashburton District Community Plan. To date $200 \mathrm{~km}$ of race has been closed.

${ }_{11}$ Two reports were prepared to assess the impact on supply reliability (U04/15/1) and the economic impact (U04/15/2) of proposed management options for the Ashburton River/Hakatere.
} 
is estimated at about $\$ 6.86$ million $^{12}$ cash farm surplus per year. The annualised cost of upgrading stockwater systems (individual or community supply, piping etc.) was estimated at $\$ 1.56$ million. Using these figures there is a cost benefit ratio of 1:4. From an economic viewpoint there appears to be significant benefit to the community to better utilise the water that is currently being taken for stockwater supply, This is provided for in the NRRP, but with a provision that $20 \%$ of the water that is freed up from stockwater be surrendered. This latter provision helps offset the effect of the changed flow regime on existing irrigators supply reliability.

\section{Status of resource consents applications to take from a Schedule WQN1 allocation regime.}

Where a surface water body is included in Schedule WQN1 and there is still water available for allocation in the A block, such an activity will be a controlled activity, and as such provides the certainty that the application will be granted although it will be subject to certain conditions. Activities to take water from a "B" or any other block will be restricted discretionary and so may be granted or declined, and if granted, subject to conditions.

Once an allocation block limit is set in Schedule WQN1 and it is fully allocated, it is a prohibited activity to apply for a take from this block ${ }^{13}$.

\section{Interim allocation regimes}

Schedule WQN2 provides an interim approach to establishing allocation regimes.

By way of background the approach for determining interim allocation limits was developed from the Lincoln Environmental work. For the Rangitata, Waimakariri and Ashburton rivers a flow (reference flow) was found that occurs at each level of reliability and the minimum flow was deducted to provide the allocable amount for each river and each reliability level. Having derived results for these three rivers, ECan asked if the results could be reanalysed to give a simpler approach that could be applied more generally.

What was developed was that a flow duration curve be derived for each river for the most critical months of January and February ${ }^{14}$ and that the frequency of the reference flow be determined from this flow duration curve. This percentage figure is referred to as an indicator flow statistic (IFS). The IFS varies for each river, land use and reliability option. The assumption that we hoped would prove true was that the IFS would be common for each river type. The Lincoln Environmental report (U01/ 1) recommended further work to test this.

The second report by Lincoln Environmental (U03/9) undertook this, along with a review of the original approach. We sought an assessment of lowland, volcanic, and spring-fed river types and also assessment of another hill type river to compare with the Ashburton River/ Hakatere.

The review found no need for changes to the general methodology but did suggest and apply improvements that allowed "a greater degree of smoothing of the supply/ allocation time series and improved modelling of effects of stockwater takes". The determination of allocation limits using the rigorous approach was done and an IFS was determined for some but not all the rivers tested. Deriving an unmodified record for lowland rivers was not possible and using the flow record that was derived for the Selwyn River at Coes Ford (as a spring-fed river) was not useful. The results that were obtained led to the conclusion that "there was no significant correlation between river type and the IFS". What was recommended was that a single value be chosen for all river types and this was conservatively recommended as being $85 \%$. The main proviso was that this be applied only where the combined minimum flow and stockwater takes are less than $70 \%$ of mean annual low flow (MALF).

This approach has been included in Schedule WQN2 of the Water Quantity Chapter of the proposed NRRP. This is illustrated in Figure 1.

\section{Status of resource consents applications to take from a Schedule WQN2 interim allocation regime.}

It will be a restricted discretionary activity to take water from a surface water body where the effective allocation does not exceed the interim allocation block limit. It will be a non-complying activity where the block is calculated to be fully allocated. The exceptions to this latter provision include where the application is for a replacement consent.

It will be evident from the earlier discussion that there will be occasions where an allocation block limit cannot be derived. In this case the application will be considered as a non-complying activity.

\section{Groundwater - allocation regimes}

For groundwater resources, interim and more permanent allocation limits are to be set. An initial approach is

\footnotetext{
${ }^{12}$ This is taken from option 8 a on Table 8 of the report by Stuart Ford (The Agribusiness Group). There is a separate figure of $\$ 10.58$ million in Table 12. In discussion with Stuart Ford we agreed that this number is used in error as it doesn't deduct the output from the dryland farming that will be replaced.

${ }^{13}$ This describes the situation once the Plan is operative. In the proposed stages of a Plan RMA s77C(1)(c) provides that a Prohibited Activity be processed as a discretionary activity.

${ }^{14} \mathrm{~A}$ number of combinations of months were tested and the months of January and February were determined to be the most critical months.
} 
Figure 1 Proposed NRRP Schedule WQN2 allocation approach.

\section{Determination of interim A allocation limits}

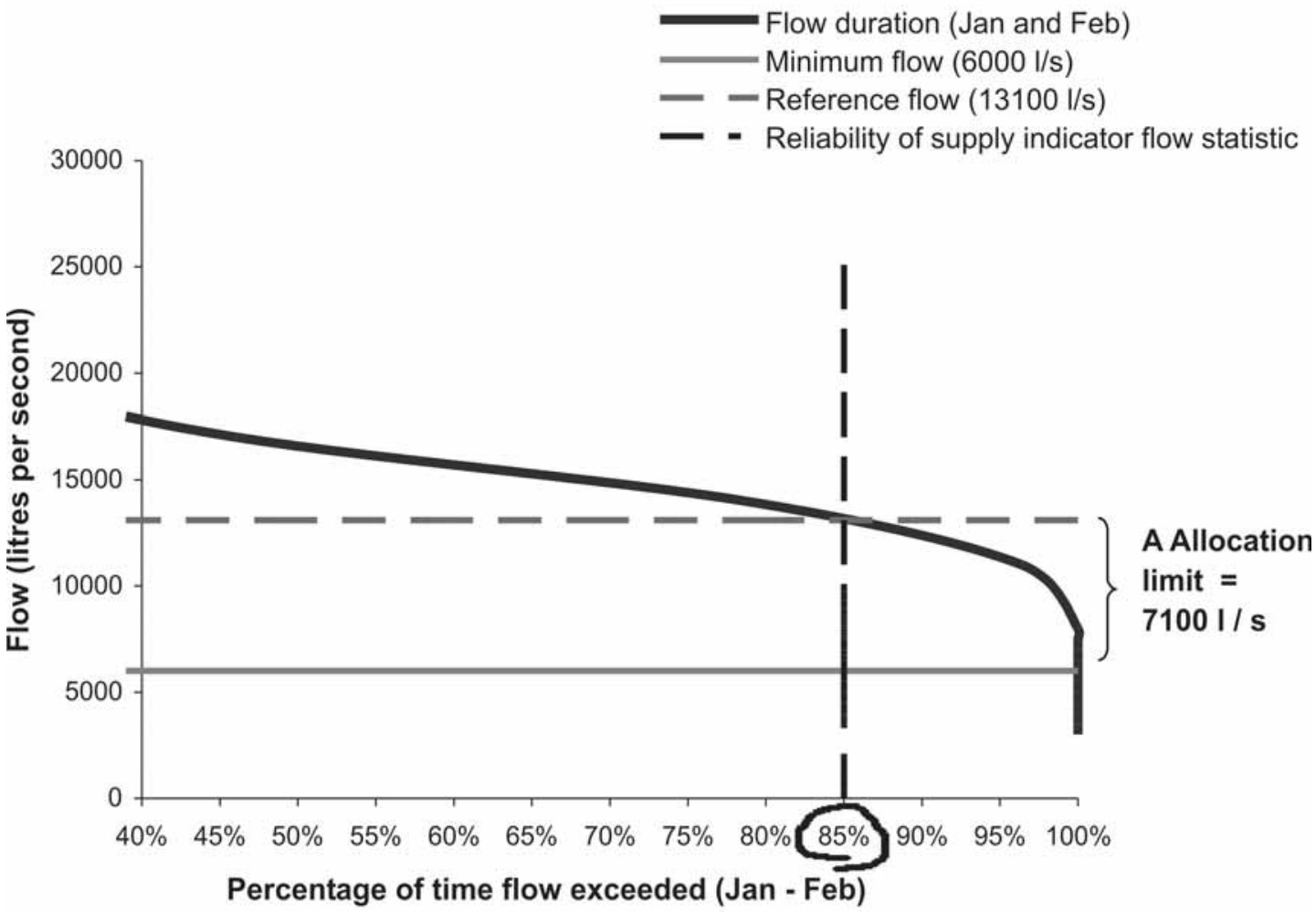

included in Schedule WQN4, and with further understanding and refinement specific groundwater allocation regimes will be included in Schedule WQN3.

In the NRRP, ECan has set reliability level 2 as the level to guide the setting of groundwater allocation limits. This is higher than the standard proposed for surface water. This is justified on the basis that groundwater recharge and availability is less variable than surface water and on this basis it has attracted higher value landuses that are dependent on this higher reliability. As with surface water this could vary depending on the expectations and views of the community.

It is important to note that the potential impacts of groundwater development on environmental values such as instream values of groundwater-fed streams and saltwater intrusion at the coast will need to form part of the considerations when setting allocation regimes.

Implementation of allocation regimes will require some changes to current groundwater management approaches. Annual/seasonal volumes are not generally included on water permits for the taking of groundwater (or surface water) and groundwater takes, other than those with stream depleting effects, have generally not been subject to restrictions in the past. There is provision for takes from groundwater zones with allocation regimes set in Schedule WQN3 to be allocated a seasonal volume and for this amount to be reduced at the start of the season. This could occur if recharge of the groundwater resource has not been sufficient over the winter to ensure adequate water to maintain critical water levels and supply all those who are allocated water.

Reliability level 2 is the initial guide when setting allocation limits for groundwater using Schedule WQN3. It is not so simple to use this for setting interim groundwater regimes using Schedule WQN4 because existing groundwater permits are not currently subject to restrictions. With this being the case, these existing groundwater takes have $100 \%$ reliability of supply providing the aquifer can yield their water requirements. It is not proposed to review existing permits to fit in with an interim allocation regime, so the existing reliability would not change until the regime has been set more permanently in Schedule WQN3.

The intention is to be relatively precautionary when 
Table 3 Canterbury groundwater zones allocation status.

\begin{tabular}{|c|c|c|c|c|c|c|}
\hline \multirow[t]{2}{*}{27 August 04} & $\begin{array}{l}\text { Number of } \\
\text { consents } \\
\text { in process }\end{array}$ & $\begin{array}{l}\text { Allocation } \\
\text { limit } \\
(\%)\end{array}$ & $\begin{array}{l}\text { Allocation } \\
\text { granted to } \\
\text { date }(\%)\end{array}$ & $\begin{array}{l}\text { Allocation } \\
\text { granted to } \\
\text { date (\%) }\end{array}$ & $\begin{array}{c}\text { Allocation } \\
\text { if all } \\
\text { granted (\%) }\end{array}$ & $\begin{array}{c}\text { Allocation } \\
\text { if all } \\
\text { granted (\%) }\end{array}$ \\
\hline & \multicolumn{2}{|l|}{ Consent info } & \multicolumn{2}{|c|}{ Allocation information } & \multicolumn{2}{|c|}{ Effective allocation } \\
\hline Ashburton-Lyndhurst & 29 & 111 & 102 & 92 & 113 & 101 \\
\hline Ashburton River & 30 & 69 & 50 & 73 & 60 & 87 \\
\hline Chertsey & 74 & 89 & 90 & 101 & 130 & 146 \\
\hline Levels Plain & 12 & 30 & 32 & 106 & 34 & 113 \\
\hline Mayfield-Hinds & 25 & 123 & 47 & 38 & 59 & 48 \\
\hline Orari-Opihi & 18 & 71 & 52 & 74 & 60 & 85 \\
\hline Pareora & 4 & 20 & 11 & 54 & 11 & 55 \\
\hline Rangitata-Orton & 13 & 32 & 50 & 152 & 57 & 173 \\
\hline Valetta & 55 & 99 & 89 & 90 & 120 & 121 \\
\hline Waihao-Wainono & 5 & 26 & 8 & 33 & 10 & 38 \\
\hline South total & 265 & & & & & \\
\hline Ashley & 5 & 25 & 21 & 83 & 22 & 87 \\
\hline Eyre River & 12 & 81 & 55 & 68 & 57 & 70 \\
\hline Rakaia-Selwyn & 78 & 208 & 233 & 111 & 251 & 120 \\
\hline Waimakiriri-Selwyn & 55 & 131 & 131 & 99 & 147 & 111 \\
\hline North total & 150 & & & & & \\
\hline Combined total & 415 & & & & & \\
\hline
\end{tabular}

fixing the interim allocation limit for groundwater. The policy describing the approach for setting interim groundwater allocation limits has been worded to refer to "using a precautionary approach to protect environmental values sustained by groundwater levels, such as flows and levels in rivers, lakes, springs or wetlands."

The Lincoln Environmental report U01/1 tested two approaches for setting groundwater allocation limits. One was to allocate $50 \%$ of the annual average recharge that occurs at the three levels of reliability, i.e. high threshold reliability achieved $5 / 5$ years, $4 / 5$ years and $3 / 5$ years with limits on the frequency of the low threshold occurrence. The other approach was to fix a constant amount for the aquifer and allocate recharge in excess of this.

The Canterbury Strategic Water Study also sought to develop sustainable yield limits for the main groundwater areas of Canterbury ${ }^{15}$. In order to make an initial calculation, the study looked at the impacts on springfed streams as an indicator of the cumulative effects of groundwater abstraction. As an approach, it proposed that an allocation limit could be set that would allow total abstraction to lower groundwater which would, in turn, change the flow regime of an affected surface water body. As a starting point, it proposed that the extent of change could be measured as the increase in the proportion of time the flow is below the current median flow from
$50 \%$ to $70 \%$.

The study also identified the net use effect of irrigation. This demonstrated that irrigation will allow more rainfall and/or irrigation recharge water to contribute to groundwater recharge, potentially allowing more water to be allocated.

With these thoughts in mind ECan has refined the NRRP approach for determining the interim groundwater allocation limits. The effect on environmental values such as stream recharge and spring flows are accommodated by the intention to retain all of the constant recharge within the groundwater system and to allocate a proportion of the variable recharge component.

The first order approach is to be used when there is very little information about a particular groundwater resource. Where this is the case, the only variable component of recharge that is likely to be able to be estimated is rainfall. The first order approach allocates $50 \%$ of the amount of rainfall that is estimated to contribute to groundwater recharge.

Where more information is available for a particular groundwater resource, the second order approach allows for more inputs to be estimated and counted as contributing to the variable recharge component and allows for $50 \%$ of this to be allocated. So, as well as rainfall, the additional inputs include irrigation recharge and recharge coming from intermittent streams.

The first order approach has been applied to the

\footnotetext{
${ }^{15}$ The study discussed the definition of "sustainable yield" and noted that the definition has taken on the meaning of the amount that can be abstracted from an aquifer for which the total range of consequences (environmental, social and economic) is acceptable.
} 
groundwater zones across Canterbury and where possible, estimates of other variable recharge components were added. ${ }^{16}$. This was reported to Council in February 2004. Application of the first order approach identified seven zones where the interim allocation limit was exceeded by the effective allocation. These areas have been referred to as "red" zones. When estimates of other variable recharge components were added this reduced the number of red zones to four. Subsequent refinement and more resource consent applications for water has changed the status of some of these again. Table 3 illustrates the status of these zones at 27 August 2004, along with the number of consents in process at that time.

It would be desirable that there are clear cut limits that don't change. This is the aim of setting regimes in Schedule WQN3, but in the interim there will be change.

A key concept in what has been developed is that of "adaptive management". As more information becomes available we should move towards a more definitive allocation strategy. In the interim, where there is less information about the resource, yet development pressure is great, a simpler and possibly more precautionary approach has been proposed.

\section{Groundwater allocation zones}

For the purpose of setting groundwater allocation limits, twenty-nine groundwater allocation zones have been described across the region. The basis for these is described in report U04/2. These are defined for interim allocation purposes. It is conceivable that these zones could be redefined and in particular divided into more discreet zones when brought into Schedule WQN3.

\section{Effective allocation}

The allocation limit for surface water is set as a flow rate while the allocation limit for groundwater is set as an annual volume. The effective allocation is the amount of water that is to be counted as being allocated from the allocation block. When the effective allocation equals or exceeds the allocation limit the block is full (highly allocated, over-allocated). In this situation, depending on the status of the allocation regime, it will be a noncomplying activity or a prohibited activity to take more water. The non-complying status applies to interim allocation regimes, where there is still some potential room for change in the allocation block limit. The Prohibited activity status applies to the allocation regimes that are set in Schedule WQN1 or Schedule WQN3. This means that once the plan is operative an application cannot be made to take water from this block nor can it be granted. There are some provisos that go with this. Existing irrigators would be able to seek a replacement consent from the same allocation block, small takes that are permitted activities can still be established and consents could be sought for activities that don't affect the allocation regime.

The determination of effective allocation is one of the problems for deciding on whether an allocation block is full. This can be determined from consent conditions providing it is there as part of the consent, and on all the consents.

For surface water bodies the effective allocation is the sum of the average rate of take of each water permit that is to be counted. For surface water takes this can be determined as the amount of water that can be taken continuously in order to take the daily volume entitlement. For groundwater takes that are to be counted because they have a high, moderate or low stream depletion effect, the average rate of take that is to be counted is the stream depletion effect.

For groundwater takes, the effective allocation is the sum of the annual volume or a proportion of the annual volume of each water permit that is to be counted. Where a groundwater take has a stream depletion effect that is to be counted as part of a surface water body allocation regime, the annual volume should be reduced by the proportion of the rate of take that is to be counted in the surface water allocation block. This should be determined at the time of assessing and issuing consents to initially determine that there is water available in both allocation blocks. Once the annual volume is determined, this amount is to be reduced to $90 \%$ of the annual volume to establish the effective allocation. If an annual volume is not set as a condition of consent, then it is to be derived in accordance with Schedule WQN9 where the take is for irrigation purposes. Schedule WQN9 has been included to allow this calculation of seasonal irrigation demand to guide decisions on reasonable use as well as set limits for allocation purposes. Currently very few consents have an annual volume specified.

\section{Seasonal allocation - reasonable use/efficiency} Efficient resource use is an important consideration in the proposed NRRP. By developing water allocation blocks there is a clear intention to limit the amount of water that can be taken. This has a real benefit to water permit holders who can secure access to water within this block. That privilege carries with it an obligation to be efficient in the use of the water. Inefficient use will deprive others of access once the block is full and it can have adverse environmental effects, particularly where it

${ }^{16}$ Two reports were presented to Council in February 2004 applying the approach and further refining the approach for inclusion in the NRRP. It was upon presentation of these that the implications of setting allocation limits became clearer around the region. 
Figure 2 Attainable application efficiencies for different system types.

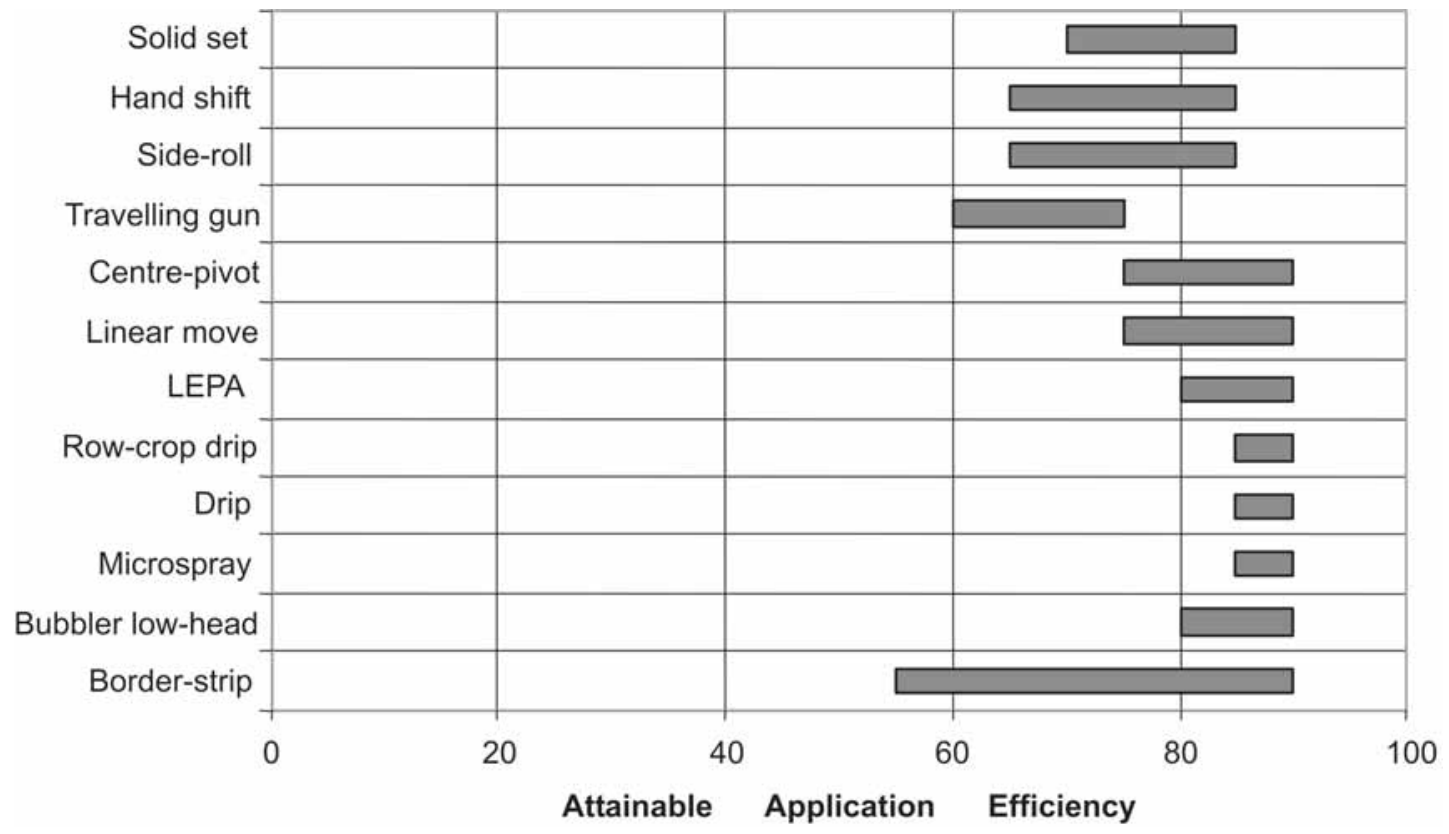

is causing leaching of nutrients and consequential contamination of ground or surface water and also where it causes nuisance in raising groundwater levels and drainage problems.

There are arguments to suggest that less efficient use of water can have beneficial effects such as recharging groundwater. While promoting efficient use, the Plan has made provision for allocating more water to an individual where it can be demonstrated that there is a real community benefit to justify less efficient practices.

Initially the plan, through the policy and rules promotes efficient use of water. Policy WQN17 targets an irrigation application efficiency level of $80 \%$. This approach doesn't focus on method of irrigation, and leaves this to the individual permit holder, although if the chosen method gives rise to clear nuisance or adverse effects the activity could be required to change or stop. From a review undertaken by Ian McIndoe ${ }^{17}$, we know that the majority of methods, including border dyke irrigation can achieve this level of efficiency. This report included the Figure 2 above ${ }^{18}$.

The brief for the McIndoe report was to look at water use and efficient application of water, report on definitions, efficiency standards and on ways of measuring efficiency in relation to irrigation. The report recommended the use of the term "irrigation application efficiency" and defined it, and recommended targeting an application efficiency of $80 \%$ for all irrigation systems. It also recommended that consent conditions relating to reasonable and efficient use should include:

- Allowable peak rate of take (in $1 / \mathrm{s}$ or equivalent);

- Seasonal volumes of water allowed to be taken, based on reasonable use;

- Monitoring to determine peak rate of take at a frequency appropriate to the use of data and potential effects on the environment;

- A requirement to submit volume of water used each season.

These recommendations have generally been incorporated into the NRRP approach.

Seasonal water requirements were included in this report and ECan looked to apply these in further policy development. However when applying them to assist in determining effective allocation they seemed to overstate the amounts that would be required. Our understanding was that these figures didn't reflect what was actually being used, and had been derived using irrigation simulation modelling rather than from actual use data. We asked Tony Daveron to review this work and to suggest an alternative approach to define seasonal volumes based on his soil moisture monitoring work. The seasonal irrigation demand values in Schedule WQN9 are based on the work reported on in Report U03/56 and on the additional information for seasonal irrigation demand

\footnotetext{
${ }^{17}$ Ian McIndoe "Efficient and Reasonable Use of Water for Irrigation" Report U01/69.

${ }^{18}$ This table is sourced from A. J. Clemmens (US Water Conservation Laboratory USDA Agriculture Research Centre, Phoenix Arizona) in his paper "Measuring and Improving Irrigation System Performance at the Field Level".
} 
for arable and horticultural crops prepared for Environment Canterbury by Tony Davoren, and adjusted for an application efficiency of $80 \%$.

The standards set in Schedule WQN9 have been set to meet demand conditions four years out of five, that is, $80 \%$ of the time. This corresponds to the reliability of supply standard recommended in Policy WQN14 for setting of an A allocation block limit for groundwater.

Using 30 years of estimated irrigation net-use data, the irrigation season 1998/1999 is determined to represent such demand conditions.

The results of the comparison (see Table 6, Appendix 2 ) between the computer simulation and the quantities derived from the soil moisture records (Report U03/56) show that generally the values derived from the computer simulations show a higher seasonal irrigation demand than what has actually been measured in the field via soil moisture data. This is thought to be because farmers using soil moisture monitoring receive and/or make irrigation management decisions based on the current soil moisture deficit, the forecast weather and they vary the amount of water applied. The computer simulation by contrast does not consider future weather (other than historical evapotranspiration), applies a constant depth of irrigation, irrigates the next paddock in a fixed order and has a fixed irrigation rotation of twelve days.

On this basis, the seasonal irrigation demand values derived from actual soil moisture monitoring reflecting objective irrigation management decisions are being recommended for use as standards for permitting water use, without the need for a resource consent. Where these are exceeded, the use of water is a discretionary activity and the need for more water will have to be justified.

Table 4 below is included in Schedule WQN9 of the NRRP and sets out the standards for seasonal irrigation demand.

\section{Stream depletion effects}

Stream depletion has been mentioned earlier and the topic deserves a paper in itself. A brief discussion is provided here to explain the links with the surface and groundwater allocation strategies.

Takes from shallow groundwater in close proximity to rivers and streams will have an effect on surface water bodies. Policy in the NRRP has classified different degrees of hydraulic connection and established how these are to be managed. Essentially there are three categories defined. These are high, moderate and low. Figure 3 includes an illustration of these categories and illustrates the range of effect on surface water flows that they can have.

The effect of a take with a high degree of hydraulic connection on surface water will develop rapidly. Most of the water taken will be sourced from the river. The effect of a moderate degree of hydraulic connection on the surface water body will be slightly to reasonably

Table 4 Seasonal irrigation demand standards.

\begin{tabular}{|c|c|c|c|c|c|}
\hline Soil category & $\begin{array}{l}\text { Soil type } \\
\text { example }\end{array}$ & $\begin{array}{l}\text { Demand } \\
\text { conditions }\end{array}$ & $\begin{array}{c}\text { "Peak" design } \\
\text { demand } \\
\text { (mm/day) }\end{array}$ & $\begin{array}{c}\text { System capacity } \\
\text { to meet peak } \\
\text { demand }(\mathrm{l} / \mathrm{s} / \mathrm{ha})\end{array}$ & $\begin{array}{c}\text { Seasonal } \\
\text { irrigation } \\
\text { demand }(\mathrm{mm})\end{array}$ \\
\hline \multicolumn{6}{|c|}{ Intensive pasture } \\
\hline Light, shallow & Lismore, Eyre & $\begin{array}{l}\text { High } \\
\text { Medium } \\
\text { Low }\end{array}$ & $\begin{array}{l}5.5 \\
5.0 \\
4.5\end{array}$ & $\begin{array}{l}0.80 \\
0.72 \\
0.65\end{array}$ & $\begin{array}{l}560 \\
320 \\
320\end{array}$ \\
\hline Medium & $\begin{array}{l}\text { Shallow } \\
\text { Templeton, } \\
\text { Chertsey }\end{array}$ & $\begin{array}{l}\text { High } \\
\text { Medium } \\
\text { Low }\end{array}$ & $\begin{array}{l}5.5 \\
5.0 \\
4.5\end{array}$ & $\begin{array}{l}0.80 \\
0.72 \\
0.65\end{array}$ & $\begin{array}{l}450 \\
315 \\
315\end{array}$ \\
\hline Heavy, deep & $\begin{array}{l}\text { Wakanui, } \\
\text { Temuka, } \\
\text { Templeton }\end{array}$ & $\begin{array}{l}\text { High } \\
\text { Medium } \\
\text { Low }\end{array}$ & $\begin{array}{l}5.0 \\
4.5 \\
4.0\end{array}$ & $\begin{array}{l}0.72 \\
0.65 \\
0.58\end{array}$ & $\begin{array}{l}250 \\
200 \\
150\end{array}$ \\
\hline \multicolumn{6}{|l|}{ Arable } \\
\hline Light, shallow & Lismore, Eyre & $\begin{array}{l}\text { High } \\
\text { Medium } \\
\text { Low }\end{array}$ & $\begin{array}{l}5.5 \\
5.0 \\
5.0\end{array}$ & $\begin{array}{l}0.80 \\
0.72 \\
0.72\end{array}$ & $\begin{array}{l}315 \\
260 \\
260\end{array}$ \\
\hline Medium & $\begin{array}{l}\text { Shallow } \\
\text { Templeton, } \\
\text { Chertsey }\end{array}$ & $\begin{array}{l}\text { High } \\
\text { Medium } \\
\text { Low }\end{array}$ & $\begin{array}{l}5.5 \\
5.0 \\
4.5\end{array}$ & $\begin{array}{l}0.80 \\
0.72 \\
0.65\end{array}$ & $\begin{array}{l}280 \\
260 \\
260\end{array}$ \\
\hline Heavy,deep & $\begin{array}{l}\text { Wakanui, } \\
\text { Temuka, } \\
\text { Templeton }\end{array}$ & $\begin{array}{l}\text { High } \\
\text { Medium } \\
\text { Low }\end{array}$ & $\begin{array}{l}5.0 \\
4.5 \\
4.0\end{array}$ & $\begin{array}{l}0.72 \\
0.65 \\
0.58\end{array}$ & $\begin{array}{l}210 \\
200 \\
155\end{array}$ \\
\hline
\end{tabular}


Figure 3 Degree of hydraulic connection categories (the $\diamond$ symbols show the definitive criteria for discriminating between categories).

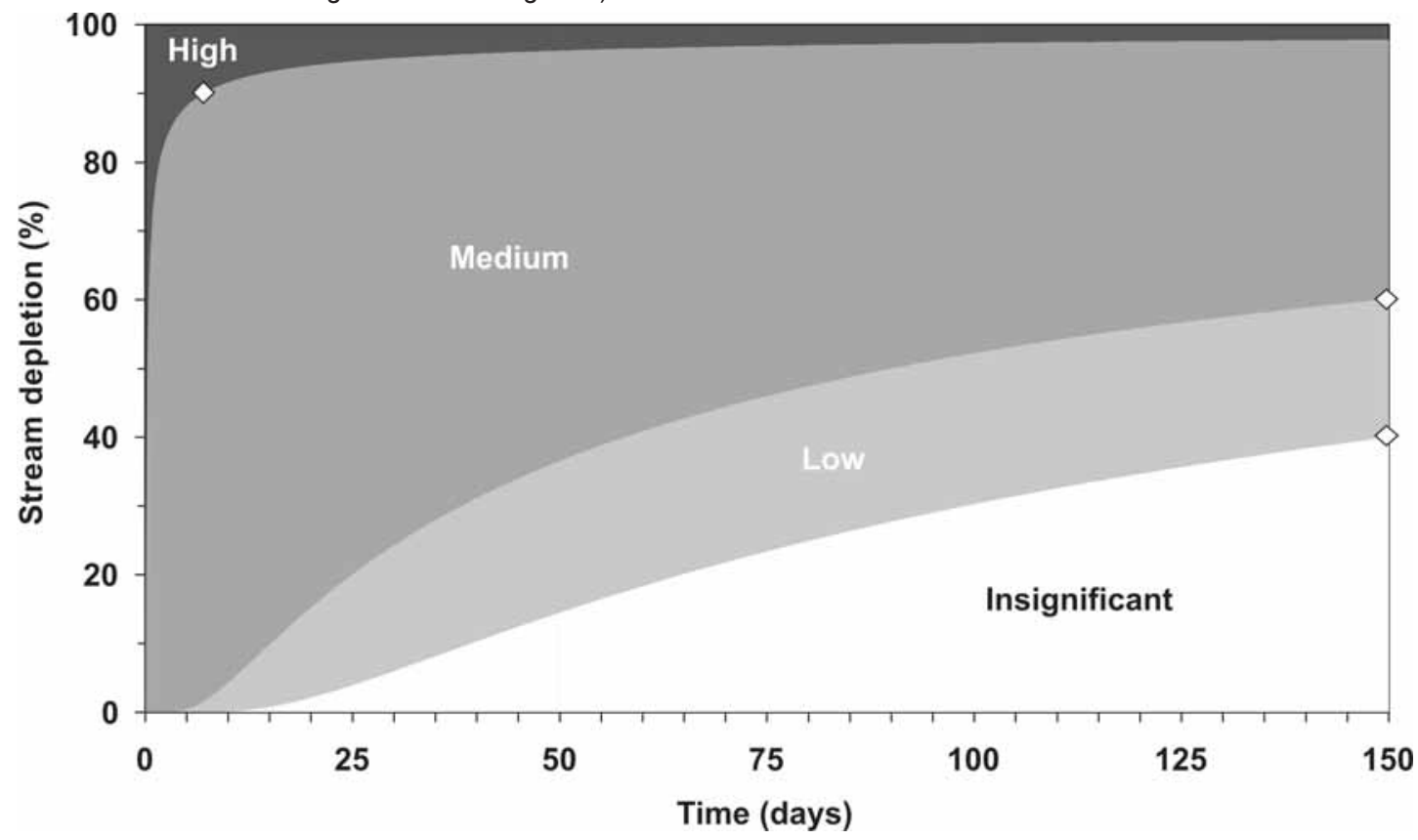

delayed. Over time a large proportion of the take will be drawn from surface water. This is set as greater than $60 \%$ after 150 days pumping at the average rate necessary to take the volume that is permitted to be taken over this period. The effect of a low degree of hydraulic connection on the surface water body will be reasonably delayed. The proportion of effect over time will range from $60 \%$ down to $40 \%$. There is a cut-off below low where there may be an effect but this is considered minor or insignificant and not worth managing from the perspective of the surface water body. In this case the entire take would be managed as a groundwater take.

Where the take is classified as having either a high or moderate degree of hydraulic connection, such takes will be subject to the relevant surface water flow regime. Where the take is moderate or low, there will be an apportioning of the water between the surface water and groundwater allocation regimes. The formula for dividing this between the surface and groundwater allocation regimes is as follows.

\begin{tabular}{|c|c|}
\hline $\begin{array}{l}\text { proportion of } \\
\text { annual volume }\end{array}$ & $\begin{array}{l}\text { annual volume } x \text { (continuous rate of } \\
\text { take - stream depletion effect) }\end{array}$ \\
\hline groundwater & continuous rate of take \\
\hline
\end{tabular}

Effectively the annual volume is reduced by the proportion that is calculated as being taken from surface water.

This approach to managing stream depletion has been developed in conjunction with ECan Environmental Monitoring - Groundwater section. The approach is further explained in the Section 32 report that has been prepared for Chapter 5.

\section{Water allocation panel}

There is a need for active management of the allocation regimes, most particularly of the interim regimes. A number of aspects can change that will change the interim allocation block limit or the effective allocation. ECan intends to maintain a data base that demonstrates the current state of play. To oversee this it is intended to operate a Water Allocation Panel. All changes will need to be managed through this panel. This is intended to ensure an open and transparent process. These decisions will not bind a resource consent hearing panel, but will be used to inform them. The hearing committee may, for example, accept evidence that there is additional water available in an area where the interim allocation block is assessed to be fully allocated.

\section{Other complications}

The focus of this water allocation approach is on irrigation. This is justified because about $84 \%$ of the water that is abstracted within Canterbury, is used for irrigation. But not counted in this is the amount of water that is used for hyrdo-electricity generation. The NRRP has recognised this complication but hasn't resolved it. We consider it needs a specific strategy where there is 
competition for water in this way. The conflict is most apparent in the Waitaki catchment and this is an issue that has been taken over by the Government.

\section{Conclusions}

Hopefully this paper has shed some light on the approach that has been included in the Natural Resources Regional Plan by ECan for managing the allocation of the regions surface and groundwater resources. The approach however, is not finalised. The proposed plan process invites submissions and these may lead to changes. There is potential for the approaches to be modified or changed significantly.

It is not a simple strategy that has been developed. Our knowledge of the resources is often limited and the amount and way that water has already authorised for abstraction and use complicates matters. The approach developed has sought to draw on the science and knowledge that is available. The approach however is not just a science. Social and economic matters are also at play. We know that individuals and communities livelihoods are going to be affected by these provisions. But they will also be affected if no action is taken.

The need for the setting of allocation limits and the clear and concise implementation and enforcement of these is becoming increasingly important as the demand for the water resource intensifies.

\section{REFERENCES}

Daveron, A. 2003. Review of Technical Reports and Assessment of appropriate peak design demand, system capacity and reasonable seasonal use. Environment Canterbury Report No. U03/56.

Environment Canterbury 2004. Variation 1 Proposed Natural resources Regional Plan, Chapter 5 Water
Quantity. Environment Canterbury Report No. U04/ $15 / 5$.

Environment Canterbury 2004. Chapter 5 Water Quantity (WQN) - Section 32 Report. Environment Canterbury Report No. U04/16/5.

Horrell, G. 2001. Ashburton River Flow Regime. Environment Canterbury. Report No U01/26.

Horrell, G. 2003. Ashburton River low flow regime review and update. Unpublished technical report. U03/28 Environment Canterbury.

Lincoln Environmental 2004. Reliability of supply for irrigation in Canterbury - Part 2. Environment Canterbury U03/9.

Lincoln Environmental 2004. Impact of the Draft NRRP flow management regime on supply reliability in the Ashburton River. Unpublished technical report. U04/ 15/1 Environment Canterbury.

McIndoe, I. 2002. Efficient and reasonable use of water for irrigation. Environment Canterbury. Unpublished report U01/69.

Morgan M.; Bidwell V, Bright J.; McIndoe I. 2002. Canterbury Strategic Water Study prepared for Environment Canterbury, MAF and MFE. Report No 4557/1.

Robb, C.; McIndoe, I. 2001. Reliability of supply for irrigation in Canterbury: ECan Report No U01/1.

The AgriBusiness Group 2004. The economic impact of proposed management options of the Ashburton Hakatere River. Unpublished technical report. U04/ 15/2 Environment Canterbury.

Veltman, A.; Miller, M.; Glennie, J.; Talbot, J. 2004. Draft Natural Resources Regional Plan groundwater allocation policy implementation - analysis and implications. Environment Canterbury Report No. $\mathrm{U} 04 / 18$. 
Table 5 Ashburton River/Hakatere effective allocation.

\begin{tabular}{|c|c|c|c|c|c|}
\hline & $\begin{array}{l}\text { Groundwater } \\
\text { SD effect } \\
(>5 \mathrm{l} / \mathrm{s})\end{array}$ & $\begin{array}{c}\text { Surfacewater } \\
\text { Max } \\
(\mathrm{I} / \mathrm{s})\end{array}$ & $\begin{array}{l}\text { Totals } \\
\text { Avg } \\
(\mathrm{I} / \mathrm{s})\end{array}$ & $\begin{array}{c}\operatorname{Max} \\
(\mathrm{I} / \mathrm{s})\end{array}$ & $\begin{array}{l}\text { Avg } \\
(1 / s)\end{array}$ \\
\hline Stony Creek & & 113 & 113 & 113 & 113 \\
\hline Woolshed Creek & 5 & & & 5 & 5 \\
\hline Ashburton River South Branch above Valetta & 5 & 8934 & 8874 & 8939 & 8879 \\
\hline Ashburton River South Branch below Valetta & 155 & 823 & 162 & 978 & 317 \\
\hline Taylors and Bowyers Streams & 71 & 2436 & 650 & 2507 & 721 \\
\hline Langdons Creek and Tributaries & 19 & 162 & 151 & 181 & 171 \\
\hline South Ashburton Total & 255 & 12468 & 9951 & 12723 & 10206 \\
\hline Pudding Hill Stream & & 509 & 510 & 509 & 510 \\
\hline Mt Harding Stream & 52 & 640 & 600 & 692 & 651 \\
\hline Oshea Creek & 118 & 1200 & 897 & 1318 & 1015 \\
\hline Ashburton River North Branch & 167 & 1856 & 1378 & 2023 & 1545 \\
\hline North Asburton Total & 337 & 4205 & 3384 & 4542 & 3721 \\
\hline Ashburton Mainstem & 58 & 134 & 111 & 192 & 169 \\
\hline Carters Creek/ Laghmor Creek & 35 & 442 & 401 & 477 & 436 \\
\hline Mainstem Total & 93 & 576 & 511 & 669 & 604 \\
\hline Ashburton Catchment & 685 & 17249 & 13847 & 17934 & 14531 \\
\hline
\end{tabular}

Table 6 Comparison of seasonal irrigation demand derived from computer simulations and soil moisture analysis (based on Table 3 - Report U03/56).

\begin{tabular}{|c|c|c|c|c|}
\hline Land use & $\begin{array}{l}\text { Soil/rainfall } \\
\text { Zone }\end{array}$ & $\begin{array}{c}\text { Seasonal volume } \\
\text { based on } \\
\text { computer } \\
\text { simulation } \\
\text { U01/1 } \\
\left(\left(\mathrm{m}^{3} / \mathrm{ha}\right) \&\right. \\
\text { (mm/year) in } \\
\text { brackets }\end{array}$ & $\begin{array}{c}\text { Effective } \\
\text { irrigation based } \\
\text { on soil moisture } \\
\text { monitoring } \\
\text { U03/56 } \\
\text { (mm/year) }\end{array}$ & $\begin{array}{c}\text { Total irrigation, } \\
\text { AE of } 80 \%\end{array}$ \\
\hline \multirow[t]{4}{*}{$\begin{array}{l}\text { Intensive } \\
\text { pasture }\end{array}$} & $\begin{array}{l}120 \mathrm{~mm} \text { WHC, high } \\
\text { rainfall }\end{array}$ & $4000(400)$ & $\begin{array}{c}120-200 \\
(4)\end{array}$ & $150-250$ \\
\hline & $\begin{array}{c}\text { 120mm } \mathrm{WHC}, \text { low } \\
\text { rainfall }\end{array}$ & $7000(700)$ & $\begin{array}{c}\text { No comparable } \\
\text { data }\end{array}$ & $\begin{array}{c}\text { No comparable } \\
\text { data }\end{array}$ \\
\hline & $\begin{array}{l}60 \mathrm{~mm} \text { WHC, high } \\
\text { rainfall }\end{array}$ & $6000(600)$ & $200-250$ & $250-315$ \\
\hline & $\begin{array}{c}60 \mathrm{~mm} \text { WHC, low } \\
\text { rainfall }\end{array}$ & $8000(800)$ & $350-450$ & $440-560$ \\
\hline \multirow[t]{4}{*}{$\begin{array}{l}\text { Arable } \\
\text { cropping }\end{array}$} & $\begin{array}{l}120 \mathrm{~mm} \text { WHC, high } \\
\text { rainfall }\end{array}$ & $4000(400)$ & $\begin{array}{c}\text { No comparable } \\
\text { data }\end{array}$ & $\begin{array}{c}\text { No comparable } \\
\text { data }\end{array}$ \\
\hline & $\begin{array}{c}\text { 120mm WHC, low } \\
\text { rainfall }\end{array}$ & $5000(500)$ & $50-250$ & $65-315$ \\
\hline & $\begin{array}{c}60 \mathrm{~mm} \text { WHC, high } \\
\text { rainfall }\end{array}$ & $4500(450)$ & $125-230$ & $155-290$ \\
\hline & $\begin{array}{l}60 \mathrm{~mm} \text { WHC, low } \\
\text { rainfall }\end{array}$ & $5000(500)$ & $150-280$ & $190-350$ \\
\hline \multirow{4}{*}{$\begin{array}{l}\text { Horticulture } \\
\text { (potatoes, } \\
\text { onions, } \\
\text { process } \\
\text { vegetables) }\end{array}$} & $\begin{array}{l}120 \mathrm{~mm} \text { WHC, high } \\
\text { rainfall }\end{array}$ & $3500(350)$ & $\begin{array}{c}\text { No comparable } \\
\text { data }\end{array}$ & $\begin{array}{c}\text { No comparable } \\
\text { data }\end{array}$ \\
\hline & $\begin{array}{c}\text { 120mm WHC, low } \\
\text { rainfall }\end{array}$ & $5600(560)$ & $75-250$ & $95-315$ \\
\hline & $\begin{array}{l}\text { 60mm WHC, high } \\
\text { rainfall }\end{array}$ & $4800(480)$ & $60-170$ & $75-215$ \\
\hline & $\begin{array}{c}\text { rainfall } \\
\text { ramm } \mathrm{WHC} \text {, low }\end{array}$ & $6500(650)$ & $450-400$ & $65-500$ \\
\hline
\end{tabular}

